\title{
An Overview of the Homeschooling in Brazil: Analysis of Its Principles and Attempts of Legalization
}

\author{
Luciane Muniz Ribeiro Barbosa \\ School of Education, University of Campinas, Campinas, Brazil \\ Email: lumuniz@unicamp.br
}

Received 26 February 2016; accepted 25 April 2016; published 28 April 2016

Copyright (C) 2016 by author and Scientific Research Publishing Inc.

This work is licensed under the Creative Commons Attribution International License (CC BY). http://creativecommons.org/licenses/by/4.0/

c) (i) Open Access

\begin{abstract}
Homeschooling is a kind of education that is growing. The goal of this study is to review issues used against attempts to legalize homeschooling in Brazil, which have brought up questions about what the right to education is. It presents some themes and concepts of the New Institutionalism Theory in Education as an attempt to relate them to the debate that goes around the growth of the homeschooling movement in different places as well as a context connected to the "concerted cultivation" concept. Thus, this paper suggests that emergence of homeschooling in Brazil is not associated to the school choice movement, but to the growth of concerted cultivation and represents for the country a movement with strong political implications.
\end{abstract}

\section{Keywords}

Homeschooling, Right to Education, Concerted Cultivation

\section{Introduction}

Homeschooling is a kind of education that has been increasing in many countries. In the United States, the number of homeschooling adepts has already reached more than 2 million school-age students, according to the National Home Education Research Institute ${ }^{1}$. In Canada, with a yearly average growth rate of more than 5 percent, homeschooling is on the rise. A recent Fraser Institute study² shows that, from 2006 to 2012, homeschooling increased by 29 percent while government school enrolment reduced 2.5 percent. In countries where homeschooling is illegal, attempts to make it legal keep growing, as well as the number of families which have de-

\footnotetext{
http://www.nheri.org/.

${ }^{2}$ http://www.fraserinstitute.org/article/home-schooling-rise-canada.
} 
cided to do it in a hidden and illegal way, like the case reported in Germany [1] and Brazil [2] for instance.

This paper analyzes the principals and the basis of homeschooling, as well as its possible regularization in Brazil. The demand for such analysis arose from attempts to legalize homeschooling in Brazil, a country where education and school attendance is compulsory. This phenomenon has incited several actions: on the Judiciary, on the presentation of Bills for its regulation and an interest of society in an alternative way of teaching their kids, not to mention the debates and reflections on the subject. Following international tendencies in favor of the regularization of homeschooling, people who defend teaching at home in Brazil have reclaimed international documents of Human Rights Protection to require the priority of parents over their children's education and organized associations to exert influence over the legislature and advertise the topic for the society.

Taking this into account, this paper also makes a correlation between the growth of the homeschooling movement and the large context that involves the impact of social changes in the educational system. Thus, the debate on homeschooling practices and growth will be analyzed regarding two themes: the social organization of schooling, highlighting the new institutionalism in educational theory; and the inequalities that have emerged in the school system, with a relation between homeschooling and the "concerted cultivation" term.

The methodology used was the qualitative approach with bibliographic research, analysis of legal documents and interviews with Brazilian families that teach their kids at home. The legal Canadian homeschool experience was also used to discuss what homeschool associations and parents are doing to socialize their children and how they are creating a new sight about citizenship, factors which have questioned the compulsory component of school education and broadened the debate on the nature of the right to education. Furthermore, understanding better how these issues have been addressed in Canada can be helpful in analyzing the arguments for and against the approval of homeschooling in Brazil and providing further reflections about the right to education and its research questions.

Finally, this paper presents some research questions raised from the announced debate and proposals in order to promote investigation for future research. All of these discussion reviewing homeschooling issues also show the need of an analysis of the purpose of education and of what the implications for Brazilian educational policies are.

\section{Compulsory Education in Brazil and Attempts to Homeschooling}

The Brazilian Federal Constitution demand that education is primarily the State's responsibility and also the family's, which leads to the interpretation that Education in Brazil is compulsory from 4 to 17 years old, which covers kindergarten, elementary and high school education. In addition to that, the Law of Directives and Bases of Education (LDB 9496/1996) and the Statute of Children and Adolescents (Law 8069/1990) states that it is the duty of parents to register their children at school, during school age.

However, even within this legal context, there is a movement arising in favor of homeschooling. The number of Brazilian families that decided to teach their children at home has been increasing. These experiences have contributed to the emergence of proposals in favor of changes in the law and have brought up questions about what the right to education is and if it can be understood as the same as the right to schooling.

According to the Associação Nacional de Educação Domiciliar (Home Education National Association), founded by advocates of homeschooling to assist these families, there are about 2500 families practicing homeschooling in Brazil ${ }^{3}$. This data is difficult to confirm once these practices are illegal and clandestine.

However, cases of families were taken to court, requiring the legal action pertaining homeschooling. Their battle was broadcasted nationwide. In 2001, a family from central Brazil filed a lawsuit to acquire the right to educate their daughters at home. In the same year, they lost the lawsuit filed in the Supreme Court and were forced to register the children in school. The Supreme Court used the argument that school attendance is mandatory according to the Brazilian Federal Constitution, which presents school not only as a place to acquire knowledge, but also as a means to socialization, and develop citizenship.

Nonetheless, more recently (2010), the case of other Brazilian family, was initially accepted by local justice. This case is still under the supervision of the local education department of the city where the family lives. With regard to the Judiciary, given the innovative nature of this problem, there appears to be a non-consolidation of a jurisprudence on the matter throughout the country, which contributes to the existence of different decisions at

\footnotetext{
${ }^{3}$ http://www.aned.org.br.
} 
local bodies [2].

In addition to these cases, since 1994, seven attempts to pass a bill and one Constitutional Amendment Proposal have been submitted to the Chamber of Deputies, requesting legislation on this matter. If the bill passes there will an amendment of the Law of Directives and Bases of Education and the Statute of Children and Adolescents in order to regulate home education in Brazil. The Constitutional Amendment Proposition includes proposals for insertion, authorization and allowance of homeschooling in the Brazilian Federal Constitution.

The main proponents of these projects state that many countries where homeschooling is allowed have shown good results from homeschooled students and the International Laws, which govern Human Rights, state that the parents must have the right to choose the kind of education they want for their children. These advocates also question the validity of the Brazilian Federal Constitution regarding compulsory attendance, due to the precedence of international laws.

However, most of these bills were not passed and the decisions taken show a favorable position towards the school as the institution to promote socializing between different individuals with different cultures and ideas; therefore, fulfilling the constitutional goal of teaching citizenship alongside academic content teaching [3]. These are some arguments used by the Brazilian Supreme Court and other countries (such as Germany) in rejecting the homeschooling.

According to Arai [4], the most sophisticated argument against the parental choice in education that includes the choice to home school was presented by Eammon Callan [5]. He believes that a true common school that offers a common curriculum provides the best way of ensuring "a vibrant sense of citizenship among present and future generations. This sense of citizenship is built around the virtues of a critical tolerance of diversity, the power of rational thought and argument, and commitment to a defensible moral code" [4].

According to this point of view, if children are educated outside of school, they can be at a disadvantage, because it is through common schooling that qualities such as tolerance and the sense of citizenship are best developed. Callan [5] also states that "schooling as the great sphere should be mandatory for all children, except in some clearly defined circumstances. The reason is that the preservation of a liberal democratic state depends on it” [5]. Therefore, based on these arguments, the right to school attendance should be part of the right to education for all children.

This idea was also discussed by Monk [6] when analyzing a German case of homeschooling that was rejected by German authorities and by European Commission of Human Rights. According to him, concerns about socialization and the view that "a consequence of being home educated is a denial of the possibility of developing one's personality in conjunction with others" [6], leads to attempts to "interpret 'education' in such a way as to require school attendance. (...) it can be argued that no parent is capable of ensuring the education of his or her child at home and that in effect school attendance is essential for 'education'” [6].

As it could be expected, homeschooling advocates reject these arguments, saying that school does not have the monopoly on socialization, diversity and development of good citizens. Despite of all criticism to the lack of socialization and lack of citizenship education, to which homeschooling children would be exposed, recent researches, interviews and literature show that these concerns need to be further reviewed. While these concerns have been raised since the 90's, now they can be addressed on a more empirical basis, less hypothetical.

Dr. Van Pelt's [7] research results seems to be the consensus among Canadian homeschoolers to prove that homeschooled adults do not show problems regarding socialization or citizenship education. Contrarily, this study also aims to show they are actually better in this area than their peers. However, before generalizing these results, two aspects should be emphasized. The first one relates to the methodology used in this research. The homeschooling group were compared to the general population without adjustments for social and economic level, religious preferences, among others characteristics (for example, 95\% reported that they were Christian, a percentage much bigger than the general population, which can influence some results). The second one is that, although the results show adults with a successful social life, when asked about the worst part about being home educated, "more than one-third mentioned an aspect of the social challenges".

Furthermore, it is possible to conclude that currently, the homeschooling community still shows some concerns about socialization and citizenship education. They are showing active participation in these issues, even if it is in a different way. As Arai [4] states, they are involved in a process of developing an alternative vision of citizenship which combines a different mix of attributes in becoming good citizens, emphasizing participation in public activities and the importance of family. It does not mean it will be a better or worse kind of socialization and citizenship education, only a different way of seeing and responding to these issues. 


\section{The Homeschooling Movement and the New Institutionalism in Education}

This presents some themes and concepts of the New Institutionalism Theory in Education as an attempt to relate them to the debate that goes around the growth of the homeschooling movement in different places.

The twentieth century was marked by many transformations in schooling, especially with the emergence of modern schooling as "the lone institution that can provide a common experience for almost all of the population" [8]. Yet in the last decades it has been possible to notice how the social changes have impacted schooling in terms of goals and perspectives, organization, among other characteristics.

Schools have modernized and been through a process of change. According to Weber, this is a movement defined from "traditional authority" to "legal-rational authority". In this movement, modern schools have altered their relations with students and families (increasingly seen as clients) and their form of governance where administration became more centralized and the schools became more bureaucratic [8].

In terms of organization, many school aspects became rigidly bureaucratic, with highly structured, controlled and standardized formalities, like teacher certification, standardized courses, students subjected to a sequence plan of instruction in an age-graded school, among others. On the other hand, institutional theorists point out that this bureaucracy not always brings efficiency and not all the schools aspects are highly rationalized. Their instructional activity is less structured and not controlled. Because of that, Meyer and Rowan [9] called schools "loosely coupled": structures that are disconnected from technical activity, and activity that is disconnected from its effects. In other words, formal school structures are rationalized and bureaucratic, but technical activities, as instruction, are not [8].

In addition, when schooling is compared to the process of globalization, Meyer and Rowan [10] states that globalization has raised similarities in nation-state institutions and that schooling is not an exception in this case. The basic organization of schools has converged across nations and schools are less influenced by local initiatives and particular national needs and characteristics than by a common world culture.

Because of this change, and based on the loose coupling terminology, institutional theorists began to refer to schools as institutions that became "isomorphic". This isomorphism refers to the process by which schools become more similar, as a product of the rationalization of their formal structures, conforming to standardized expectations [8]. This process contributes to school that emerge as a dominant form of educational organization and gain support and legitimacy [9].

However, despite the logic of confidence and the legitimacy in school institutions, some people are against this bureaucracy and isomorphism. It was, for example, the case of free-schools and the deschooling movement in the 1970s. Even today there is some criticism regarding homeschooling proponents.

As an argument to the logic of confidence, Meyer and Rowan [9] state that interaction in the school system is characterized both by the assumption of good faith and the actualities of decoupling. Because of this, Stevens [11] presents parents who choose homeschooling as people who do not trust the entire educational system.

Researches points out that parents who choose homeschooling, show over time ideological and pedagogical reasons [12]. Among the pedagogical reasons, it is possible to find criticism against the bureaucratic school and its classification system and standardized form to teach students, as it was advocated by John Holt, one of homeschooling's earliest and most influential advocates [11]. Although the last decades reasons for homeschooling have been changing, the number of parents who advocate highly individualistic conceptions of learning for their children [13], against standardized ways, of learning has risen.

Despite the new institutional theorists emphasize on schools, during the 1970s and 1980s, features like loose coupled and isomorphism, "a body of theory, that identifies markets as a dramatic transformation force on schools" has emerged. These transformations are making school organizations neither uniformly isomorphic nor loosely coupled [14].

The homeschooling movement and its growth during the last decades have been usually associated with this theme also analyzed by the new institutionalism theory: the economic market impact on the institutional arrangements and, in this specific case, how "governance and market forces combine in institutional affairs to produce pressures on educational organizations" [10].

Based on that, markets became central to educational reforms. Markets reformers advocate the use of market mechanisms in order to inject a new dynamics in the school as for to make them provide effective service through competitive pressures as used by "for-profit businesses" [8].

One of these mechanisms are the school-choice arrangements. As claimed by these reformers, it reverses bu- 
reaucratic tendencies and introduces innovations in schooling by giving varied school choices to parents, also providing comparison among other school test scores, which also results in schools seeking better performance levels [8].

School choices have been growing in Canada and in the United States. In Canada, Davies and Guppy [8] state that the school choice movement is providing parents with more choice within the public school system and also in the form of private schooling. Meyer and Rowan [10] point out that, in the United States, "market like forms of education" are growing as charters schools, voucher schemes, privately managed school systems, homeschooling and others.

In spite of the differences between the school choice debate in the United States and Canada [15], both show the growth of homeschooling as one choice among several others offered to parents and within the context of the growing private education.

One consequence of the school choice politics is that, although they advocate efficiency and impose clear standards and sanctions on the school in order to force them to reach higher levels, these schools do not necessarily increase their quality and this mechanism may segregate students and worsen inequalities among students and families [8].

Another consequence, analyzed by Rowan [16], is that the introduction of school choice has had differentiated impacts on the schools population and has encouraged schools to act in various ways in order to attract clients (which, consequently show limits to theories of institutional isomorphism).

Davies et al. [14] advocates that the way markets, in general, affect school organization, is by encouraging the use of customized attention as a niche-building strategy. Then, the marketplace encourages third sector school and educators to offer a tailored and individualized educational experience, which these authors consider as the lone common denominator among several growing forms of private education in Canada, in which the homeschool is present (as also new private school and tutoring businesses).

Rowan [16] makes another statement regarding the consequence of these market arrangements in the United States education (and increasingly in other places of the world).He says that education has featured not only political matters, but also great business opportunities, where billions in the supplying of goods and services related by instruction have been spent. Added to it, Apple [17] argues that the growth of the homeschooling practice reveals the growth of a market around the homeschooling movement, which includes the activities of publishers and the virtual market production of materials that respond to the interests of different homeschooling groups.

In sum, the growth of the homeschooling movement is related to themes analyzed by the new institutionalism theory, particularly, to the impacts of the market on school organizations. These market arrangements have boosted educational reforms that contribute to the emergence and consolidation of the school choice system and, consequently, to the growth of homeschooling. In addition, due to the market impact, the homeschooling movement is growing in a context where the third sector school is rising and offering more individualized forms of education to its "clients".

\section{Homeschooling: An Extreme form of Concerted Cultivation?}

Although the growth of homeschooling has been frequently associated with some educational reforms influenced by market arrangements, as a school choice system, homeschooling also arises in a context connected to the "concerted cultivation" concept.

Annete Lareau [18] states that the social class does create distinctive parenting styles and they differ by class (and not by race) in such a way to define their own roles in their children's lives and how they perceive the nature of childhood. In this, Lareau and other sociologists, argue that the "concerted cultivation" designates "an intensive form of parenting in which middle-class parents increasingly structure their children's lives and treat them as projects-in-the-making" [15].

To middle-class parents, parenthood does not only mean to provide food and shelter, but also offer a stimulating environment: they enroll children in numerous organized activities in which they believe will give their children the most important life skills. They also stress the need for language use and the development of reasoning. According to Lareau [18], this "cultivation" results in several experiences for children (creating a frenetic pace for parents), in a cult of individualism within the family and in an emphasis on the children's performance. 
In addition, this author also emphasizes two other related consequences of this trend: well-educated parents interacting with school issues and interfering directly over decisions related to teaching (which affects the relationship with teachers) and to school organization; and an emerging "sense of entitlement" based on which parents claim for the right to act and make decisions for their children's education.

These parents, as for being involved in education, become knowledgeable of schools inner workings and are better positioned to act through school options and requirements. Because of these consequences, Davies and Aurini show school choice as a species of concerted cultivation and argue that "rationales for choice in Canada have been increasingly infused with language and ethos of concerted cultivation" and that "more affluent and educated parents are most likely to exercise choice” [15].

Despite the fact that school choice can be frequently presented as a result of educational reforms related to the market impacts, as analyzed in the earliest topic, Davies and Aurini [15] present data that link parents who advocates choice appealing to a sense of parental entitlement and not to allusions to market forces, competition or consumerism. These choice-seekers parents proclaim their "right" to possess more control over schooling and embrace more directive forms of parental involvement, with beliefs that they best know the needs of their children.

In this context, it is also possible to analyze the growth of homeschooling and argue that homeschooling is also a species of concerted cultivation, maybe in an "extreme form" in which parents also advocate the role of educator [15].

In North America, homeschooling is increasingly seen as one alternative among public schooling, private school, magnet, charter schools and others. Whether from one aspect the homeschooling growth is associated with a context of private education expansion and resembles the wider choice movement, it is, on the other hand, promoting a new-found legitimacy that is fueled by an emerging culture of intensive parenting [19].

Davies and Aurini [13] analyzed the homeschooling growth associated to a substantial growth that they called the new "third sector" private schools, which are small, specialized, and seldom oriented toward intense academic competition. These kinds of school, like many homeschoolers, focus on providing personal attention and tailored forms of pedagogy. Thus, these groups start using a highly individualized conception of child development as a point of reference and, according to these authors, the culture of intensive parenting have gripped the middle class and it has been channeling a greater variety of parents into homeschooling.

Arai [20] states that one reason for parents to choose homeschooling, both in the United States and Canada, is the intention to assert their right and responsibility for their children's education. Like choice-seeking parents, homeschoolers parents also advocate that they, more than teachers or school officials, best know what their children need and with a sense of entitlement they claim for the active and direct participation in their children education. However, Aurini and Davies [19] argue that what differ homeschooling parents from other choiceseeking parents is their insistence on the centrality of the parental authority.

Then, embedded by an emerging sense of entitlement (as adverted Lareau [18]), homeschooling parents have successfully used the language of rights and advocated homeschooling as part of an individual's freedom of conscience, and right to life and liberty nowadays. They also link homeschooling to United Nations Declarations of Human Rights in order to support parental choice in education [13].

Stevens [11] argues that, in the United States, homeschooling proponents usually legitimate theirs arguments by speaking "with some resonant chords in American culture": the belief that all people are individuals, with rights. In other countries outside North America, this belief and the use of language rights is also used by homeschooling proponents [1] [2].

In conclusion, despite the fact that the homeschooling movement is frequently associated to a school choice movement, it is possible to argue that the homeschooling growth is more related to the emergence and rise of concerted cultivation trends than to markets impacts on educational reforms.

To exemplify these arguments, homeschooling practices in the Brazilian context will be used. In Brazil, programs related to school choice movements do not exist and parents can "choose" only between public or private school. By interviewing Brazilian families who homeschooling their children it was possible to find some characteristics presented in this earlier debate: they are middle-class parents advocating for their right and responsibility to act and decide about the best education for their children. Some children are subjected to a schedule of activities that public schools do not offer and parents declare themselves very busy with their children's educational schedule [2]-[21].

Among many motivational reasons as a homeschooling support, it is possible to find some pedagogical rea- 
sons such as lack of quality in school education, dissatisfaction with the curriculum and teaching methods, general complaints to public school; and ideological reasons (concerning moral and values transmitted at school). Despite shown differences in reasons for homeschooling, all these Brazilian families advocated it using the language of individual and parent rights, based on international laws, in order to respect the freedom of choice [2].

In sum, notwithstanding the market impact on education is present in Brazil, influencing some educational reforms; but this did not mean a system of choices like in North America. Thus, the emergence of homeschooling in Brazil is not associated to the school choice movement, but to the growth of concerted cultivation. As Davies and Aurini [15] states, researches in "parentocracy" and "intensive parenting" suggest that concerted cultivation is quite international and is intensifying.

\section{Conclusion and Implications for Future Researches}

In this paper, the growth of homeschooling movement, even in countries like Brazil where it is considered illegal, was analyzed in relation with some themes presented in the new institutionalism theory and also by the concerted cultivation term.

The growth of homeschooling is presented in a context of changes in education that have boosted in the last decades, by markets arrangements and its impacts on school organization. It was possible to connect the homeschooling growth with the growth of the school choice system and also with the differentiated and individualized teaching offered by third sector school in order to attract students (or "clients").

This debate opens doors for future research. Questions such as: "does the homeschooling movement gain legitimate trough new institutionalism?”, and "how the demands of homeschooling adept to a more individualized curriculum and personalized attention in education are being legitimated by markets impacts in schools that are changing their structures and teaching in order to offer diverse options to different groups?" still need to be answered.

In addition, it is possible to suggest more research that seeks deeper and empirically as homeschooling is arising in the concerted cultivation context. Can homeschooling be proved in countries where there is no school choice system? Another aspect that should be more explored is on the inequalities presented as a consequence of the relation between the homeschooling growth and the concerted cultivation theory intensification. Within this concept one can ask: are the middle-class parents using their "sense of entitlement" to advocate one different education to their children that can become an uneven process of education among classes?

In Brazil, for example, one argument in the homeschooling debate is that whether it is legally approved in Brazil; the educational scenario may return to a historical moment when the upper class was educated at home while the good institutional education would be neglected to the poor ones [22], making educational inequalities among classes arise.

It is worth noting that given the high rates of social and economic inequalities among the population in Brazil, homeschooling does not appear as an option for everyone, but only for a small portion of the population who have the time, resources, and means to maintain a family member out of the job market to dedicate himself or herself exclusively to the education of the children at home. In addition, there is the fact that cultural, educational, sports areas and heritage are still limited and scarce within the country.

Therefore, should homeschooling be legally recognized in the country as a teaching modality to be "chosen" by parents? It will be essential that demands be made by the State for its effective implementation and supervision. Considering this fact, there are criticisms regarding the investment of public resources to meet the education in the private sector (households), and the possibility of attending only a specific class (with a given amount of purchasing power) in detriment to others (the vast majority) that, in the case of Brazil, are historically marginalized due to the economic and social problems of the country. From this perspective, the situation could get worse if some families started to request public subsidies for the practice homeschooling.

To sum up, if for the consequence of the market impact on education or by the increase of the concerted cultivation theory, homeschooling has been related to more individualized forms of education aimed at better performance of children. This fact made the debate issues rise to a new level of individualism that is changing the idea of schooling by promoting common values and showing the socialization influence of schooling as less central to individual biographies [8]. As other schools propose, added to knowledge, such as the promotion of common values through socialization or also the wider formation of citizens engaged in society, are they being developed in this new form of education? Future research on homeschooling subjects needs to be carried out in 
order to analyze it and other questions related to these themes.

As a result, new challenges have been submitted to the educational system regarding compulsory education. Assumptions about socialization are central points in the debate that presents school life as part of the right to education and have shown a specific view about the role of the state in relation of education. Schools have always been perceived as the most important agencies of socialization and compulsory schooling as the way in which liberal democratic values of tolerance and pluralism are transmitted [6]. However, if homeschoolers have being showing real and active participation in the development of a concept of citizenship education and promoting socialization to their children, as argued earlier, this view shows limitations and also can be contested.

Therefore, if Brazilian educational authorities want to keep supporting compulsory education and decide against the legalization of homeschooling, they need to present different arguments than the currently used in which schools have the monopoly of socialization and of citizenship education, at least based on the experience of nations where homeschooling is legal, such as Canada. They can maybe mention some aspects which are particular to the Brazilian reality such as social and economic inequalities that contribute to concerns regarding the approval of homeschooling and to continue to defending compulsory education. Consequently, all of this discussion reviewing homeschooling issues shows the need of a deeper analysis of the purpose of education and of what are the implications for educational policies.

In conclusion, it is recognized that the incipient nature and complexity of any debate on this issue in Brazil, makes it necessary to have scheduled researches to deepen the studies related to it, as well as corroborating with Boudens [23] view that "homeschooling is first and foremost a political issue", mainly a political positioning. Furthermore, it is worth mentioning the point of view that more than being a favorable or unfavorable position towards homeschooling and it being legalized in Brazil, it is argued that the problems that he presented with regard to school institutions, as well as the arguments in favor of these and of compulsory school attendance, contribute to a reform of the Brazilian educational system. Such a reform would impact specifically public education and would actually aim towards quality education for all, covering dimensions and objectives beyond simple academic performance.

\section{Acknowledgements}

To Dr. Scott Davies, from McMaster University, Ontario/Canada, for providing references and materials on the Canadian homeschooling movement.

\section{References}

[1] Reimer, F. (2010) School Attendance as a Civic Duty v. Home Education as a Human Right. International Eletronic Journal of Elementary Education (IEJEE), 3, 5-15.

[2] Barbosa, L.M.R. (2013) Homeschooling in Brazil: A Challenge to School? Doctorate Thesis, Universidade de São Paulo, São Paulo.

[3] Barbosa, L.M.R. (2012) Proposals Aimed at Legalizing Homeschooling in Brazil. Revista de Direito Educacional, 5, 41-58.

[4] Arai, B. (1999) Homeschooling and the Redefinition of Citizenship. Education Policy Analysis Archives, No. 5, 1-27. http://dx.doi.org/10.14507/epaa.v7n27.1999

[5] Callan, E. (1997) Creating Citizens: Political Education and Liberal Democracy. Clarendon Press, Oxford. http://dx.doi.org/10.1093/0198292589.001.0001

[6] Monk, D. (2003) Home Education: A Human Right? Evaluation \& Research in Education, 17, 63-73. http://dx.doi.org/10.1080/09500790308668299

[7] Van Pelt, D.A., Allison, P.A. and Allison, D.A. (2009) Fifteen Years Later: Home Educated Canadian Adults. Canadian Centre for Home Education, London.

[8] Davies, S. and Guppy, N. (2010) The Schooled Society: An Introduction to the Sociology of Education. 2nd Edition, Oxford University Press, Toronto.

[9] Meyer, J.W. and Rowan, B. (1978) The Structure of Educational Organizations. In: Meyer, M., Ed., Environments and Organizations, Jossy Bass, San Francisco, No. 80, 78-109.

[10] Meyer, H. and Rowan, B. (2006) Institutional Analysis and the Study of Education. In: Meyer, H. and Rowan B., Eds., The New Institutionalism and Education, State University of New York, New York, No. 8, 1-14.

[11] Stevens, M. (2001) Kingdom of Children: Culture and Controversy in the Homeschooling Movement. Princeton Uni- 
versity Press, Princeton.

[12] Spiegler, T. (2010) Parents' Motives for Home Education: The Influence of Methodological Design and Social Context. International Electronic Journal of Elementary Education (IEJEE), 3, 57-70.

[13] Davies, S. and Aurini, J. (2003) Home Schooling and Canadian Educational Politics: Rights, Pluralism and Pedagogical Individualism. Evaluation \& Research in Education, 17, 63-73. http://dx.doi.org/10.1080/09500790308668292

[14] Davies, S., Quirke, L. and Aurini, J. (2006) The New Institutionalism Goes to the Market: The Challenge of Rapid Growth in Private K-12 Education. In: Meyer, H. and Rowan, B., Eds., The New Institutionalism and Education, State University of New York, New York, 103-122.

[15] Davies, S. and Aurini, J. (2008) School Choice as Concerted Cultivation: The Case of Canada. In: Forsey, M., Davies, S. and Walford, G., Eds., The Globalisation of School Choice, Symposium Books, Oxford, 55-72.

[16] Rowan, B. (2006) The New Institutionalism and the Study of Educational Organizations: Changing Ideas for Changing Times. In: Meyer, H. and Rowan, B., Eds., The New Institutionalism and Education, State University of New York, New York, 15-32.

[17] Apple, M.W. (2006) Away with All Teachers: The Cultural Politics of Home Schooling. In: Apple, M.W., Ed., Educating the "Right" Way: Markets, Standards, God, and Inequality, Routledge, New York, 61-80.

[18] Lareau, A. (2002) Invisible Inequality: Social Class and Childbearing in Black Families and White Families. American Sociological Review, 67, 747-776. http://dx.doi.org/10.2307/3088916

[19] Aurini, J. and Davies, S. (2005) Choice without Markets: Home Schooling in Context of Private Education. British Journal of Sociology of Education, 26, 461-474. http://dx.doi.org/10.1080/01425690500199834

[20] Arai, B. (2000) Reasons for Home Schooling in Canada. Canadian Journal of Education, 25, 204-217. http://dx.doi.org/10.2307/1585954

[21] Vieira, A.O.P. (2012) "School? No, Thank You”: A Portrait of the Homeschooling in Brazil. Monograph (Graduation), Instituto de Ciências Sociais, Universidade de Brasília, Brasília.

[22] Cury, C.R.J. (2006) School Education and Home Education: Spaces of a Controversy. Educação e Sociedade, 27, 667-688.

[23] Boudens, E. (2002) Homeschooling in Brazil. Câmara dos Deputados, Brasília. 